\title{
GENETIC SYSTEMS IN ALLIUM \\ IV. BALANCE IN HYBRIDS
}

S. VED BRAT

Botony School, Oxford *

Received 29.ix.66

\section{INTRODUCTION}

GeNETic balance arises from selective co-ordination of genetically differentiated particles in the chromosome complement. In sexually reproducing flowering plants, pollen grains and developing embryos are subjected to the test of this principle. The unbalanced forms are eliminated during or before differentiation. Thus, the chromosome numbers in the pollen grains of triploid and pentaploid hybrids do not conform to the expected binomial expansion of $(I+I)^{x}$, where $x$ is the basic number of the species. Deviations from expectation arise often owing to errors of segregation and, consequently, differential genotypic balance. During mitosis, pollen grains reveal their genotypic co-ordination by a regularity of nuclear differentiation as I have found in the following structural and numerical hybrids.

$$
\begin{array}{ll}
\text { Allium paniculatum } & 2 n=2 x=16 \\
\left.\begin{array}{l}
\text { A. carinatum } \\
\text { A. rubellum }
\end{array}\right\} & 2 n=3^{x}=24 \\
\text { A. neapolitanum } & 2 n=5^{x}=35
\end{array}
$$

Allium paniculatum produces pollen grains with $(x \pm 2)$ chromosomes. The unbalanced grains usually divide later than the balanced ones. Thus they reveal their character by the time of their mitosis. In view of this property, I have made observations on the earliest and the latest phase of anther development to see if there is any correlation between the genetic constitution and the rate of development of the pollen grains.

Techniques. Young anthers were squashed in acetic orcein as stain fixative for meiosis as well as pollen grain mitosis. Only one anther was squashed at a time. The phase of anther development was estimated by the proportion of binucleate pollen.

\section{HYBRIDITY AND MEIOSIS}

The Allium paniculatum clone is heterozygous for the position of the centromere in the pair of nucleolar chromosomes (plate I, fig. a). Chiasma frequency in the p.m.c.'s is low (table I) and there are two or four univalents per cell (text-fig. I). Anaphase-I segregation is normal in only 33 per cent. cells (table 2) and the remainder show centric, chromatid and segregational errors.

* Present Address: Botany Department, Panjab University, Chandigarh-I 4, India. 
The clones of $A$. carinatum, $A$. rubellum and $A$. neapolitanum are numerical hybrids. The last two are the same as those examined by Khoshoo and Sharma (1959a, 1959b). The frequency of errors is higher (43 per cent. cells with laggards and 33 per cent. cells with bridges) in $A$. rubellum than $A$. neapolitanum, but they are of the same

TABLE I

Metaphase pairing in Allium paniculatum $(2 \mathrm{n}=16)$

\begin{tabular}{|c|c|c|c|c|c|c|c|c|c|c|c|}
\hline \multirow{2}{*}{ Associations } & \multicolumn{9}{|c|}{ Chiasmata per cell } & \multirow{2}{*}{ Total cells } & \multirow{2}{*}{$\mathrm{Xta} /$ cell } \\
\hline & 9 & Io & II & 12 & I3 & 14 & I5 & 16 & I 7 & & \\
\hline $\begin{array}{l}6 \mathrm{II}+4 \mathrm{I} \\
7 \mathrm{II}+2 \mathrm{I} \\
8 \mathrm{II}\end{array}$ & $\begin{array}{l}2 \\
\cdots \\
\cdots\end{array}$ & $\begin{array}{l}4 \\
4 \\
\cdots\end{array}$ & $\begin{array}{r}7 \\
19 \\
2\end{array}$ & $\begin{array}{r}1 \\
14 \\
20\end{array}$ & $\begin{array}{l}\ldots \\
\text { I0 } \\
\text { I5 }\end{array}$ & $\begin{array}{l}\ldots \\
\ldots \\
\text { I5 }\end{array}$ & $\begin{array}{c}\ldots \\
\ldots \\
4\end{array}$ & $\begin{array}{c}\ldots \\
\ldots \\
\mathrm{I}\end{array}$ & $\begin{array}{l}\ldots \\
\cdots \\
2\end{array}$ & $\begin{array}{l}14 \\
47 \\
59\end{array}$ & $\begin{array}{l}\text { I0.50 } \\
11.63 \\
13.20\end{array}$ \\
\hline Total & 2 & 8 & 28 & 35 & 25 & I5 & 4 & I & 2 & 120 & $12 \cdot 27$ \\
\hline
\end{tabular}

(a)
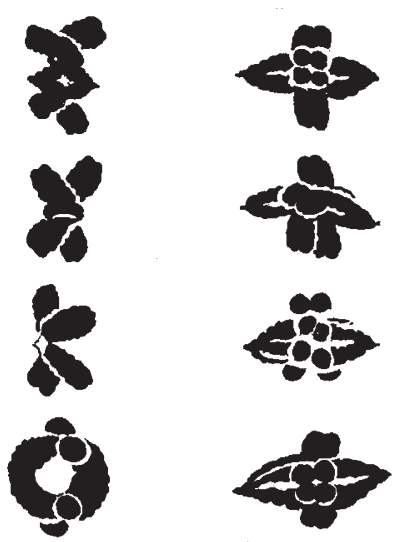

(b)
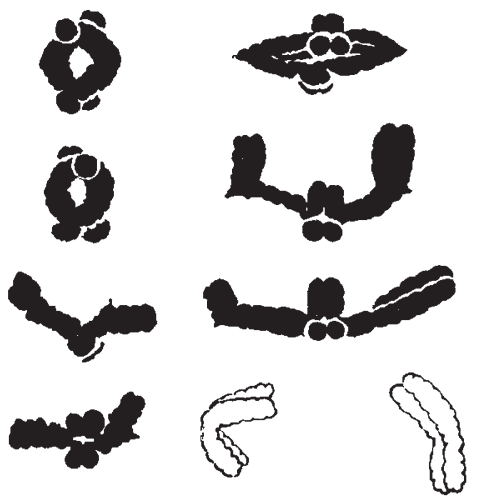

Text-Fig. I.-First metaphase in p.m.c. of Allium paniculatum hybrid. Bivalents arranged in order of decreasing chiasma frequency. $\times$ I 350
(a) $8 \mathrm{II}$,
I 5 xta.
(b) 7 II $+2 \mathrm{I}$, I I xta. 
nature as those in $A$. paniculatum, namely; misdivisions, bridges with fragments and bridges without fragments (plate I, figs. $c-f$ ).

TABLE 2

Anaphase-I distribution in Allium paniculatum $(2 \mathrm{n}=\mathrm{I} 6)$

\begin{tabular}{|l|c|c|c|c|c|c|}
\hline \multicolumn{1}{|c|}{ Distribution } & $8: 8$ & $8: \frac{1}{2}: \frac{1}{2}: 7$ & $9: 7$ & $7: 2\left(\frac{1}{2}: \frac{1}{2}\right): 7$ & I0:6 & Total cells \\
\hline Cells with & & & & & \\
\hline No bridges & 24 & 12 & 13 & 2 & I & 52 \\
\hline Bridge with fragment & 7 & 2 & 2 & $\ldots$ & $\ldots$ & I I \\
\hline Bridge only & 5 & $\ldots$ & 3 & $\ldots$ & $\ldots$ & 8 \\
\hline Total & 36 & I4 & 18 & 2 & I & 7 I \\
\hline
\end{tabular}

\section{POLLEN GRAIN MITOSIS}

(a) New chromosome types

A strikingly asymmetrical newly arisen chromosome carrying a deletion was observed only once in A. rubellum. Presumably, it arose from a chromatid error, i.e. from a bridge with or without a fragment during meiosis.

Telocentrics arising from misdivision are rather frequent in $A$. paniculatum and $A$. rubellum. As expected from the higher proportion of univalents, their frequency is higher in the latter. The pollen grains which carry newly arisen chromosomes do not always undergo mitosis. This failure is particularly common in diploids. In polyploids, although extra chromosomes have an unbalancing effect, the pollen carrying them does divide.

Survival of the telocentrics in the pollen of diploids like $A$. paniculatum, previously known in Tradescantia (Celarier, 1955) and Gasteria (Darlington and Kefallinou, I957) is important. It explains the origin of new supernumeraries (Darlington, 1958) and also new basic numbers in Allium (Levan, 1932; Ved Brat, I965). Their role in the origin of secondary trisomics is further shown by Datura (Darlington, I960). In wheat, however, the isochromosomes arise directly through misdivision at meiosis and not indirectly through non-disjunction during pollen grain mitosis. The telocentrics which are also formed survive as such during pollen grain mitosis and are transmitted to the progeny when the monosomics are selfed (Morrison, 1953).

\section{(b) Chromosome distribution in pollen grains}

(i) Structural hybrid. In A. paniculatum, pollen grain mitosis was studied from twenty-two anthers taken from eleven flower buds. Grains with six to ten chromosomes were formed (table 3). Subhaploid pollen grains undergo mitosis which is rather uncommon but 
has been reported in Uvularia (Belling, I925), Allium hybrids (Levan, 1936), heat-treated Tradescantia and its hybrids (Sax, 1937; Conger, I940; Gelarier, 1955) and also in triploid hyacinth var. Anne Marie. Recently, Lane and Evans (1966) have reported sub-haploid pollen grains as "peculiar to triploid clones" of irradiated Tradescantia.

In structural hybrids like Rhoeo selection is evident from a comparison of the segregation at first anaphase of meiosis and the chromosome numbers seen at pollen grain mitosis (Lewis and John, I964). Also, those grains which are otherwise haploid but unbalanced owing to chromosome deficiencies do not usually survive to mitosis. In $A$. paniculatum, however, the unbalanced pollen grains do reach mitosis but their chromosomes at metaphase have a hazy appearance which probably indicates their approaching death during development.

TABLE 3

Chromosome distribution in early and late dividing pollen grains of A. paniculatum hybrid $(2 \mathrm{n}=\mathrm{I} 6) . \quad$ (Numbers within brackets denote pollen grains with telocentrics.)

\begin{tabular}{|l|c|c|c|c|c|c|}
\hline \multicolumn{1}{|c|}{ Chr. No. } & 6 & 7 & 8 & 9 & 10 & Total No. of P.G. \\
Phase & & & & & \\
\hline $\begin{array}{l}\text { Early } \\
\text { Late }\end{array}$ & $\begin{array}{c}3(1) \\
4\end{array}$ & $\begin{array}{c}21_{(8)} \\
68_{(1)}\end{array}$ & $\begin{array}{c}379_{(5)} \\
50\end{array}$ & $\begin{array}{r}38 \\
7\end{array}$ & $\begin{array}{c}2 \\
\cdots\end{array}$ & $\begin{array}{c}443 \\
129\end{array}$ \\
\hline Total & $7(1)$ & $89_{(9)}$ & $4^{29(5)}$ & 45 & 2 & 572 \\
\hline
\end{tabular}

The data on early and late dividing pollen grains (table 3 , text-fig. 2) show that sub-haploid pollen grains are more frequent in the later phases but they also occur in the earlier ones. There is an extreme range of variation in the speed of their development. Also, the number of mitoses recorded from the earliest phase is very high, indicating that the pollen grains in an anther enter mitosis in a burst. This skew curve (text-fig. 2) of mitosis in the pollen grains of $A$. paniculatum may be true only of plants producing a large proportion of defective grains. It may also be found after X-raying as suggested by data on Tradescantia (Darlington and La Cour, 1945). Evidently most of the genetically weaker pollen grains divide later than the balanced ones. Lane and Evans (1966) suggest that the sub-haploid pollen grains of triploid Tradescantia enter mitosis because the pollen grains with extra chromosomes in the same anther compensate their deficiencies.

The data on individual anthers, in fact, reveal the properties of individual pollen grains, indicating that the different products of recombination in the hybrids have different rates of development and times of division. Such a correlation is also evident in Tradescantia hybrids (Conger, 1940) and Fritillaria lanceolata (Darlington, 1936). However, owing to an unusual genetic balance in Hyacinthus triploids, such a correlation does not exist. The early and late dividing pollen 
grains are homogeneous with respect to their chromosome numbers (Darlington and Mather, 1944). But this is not true for a trisomic Hyacinthus, in which only 16.5 per cent. pollen grains had the extra chromosome in anthers with less than 25 per cent. binucleate grains (Brock, 1955).

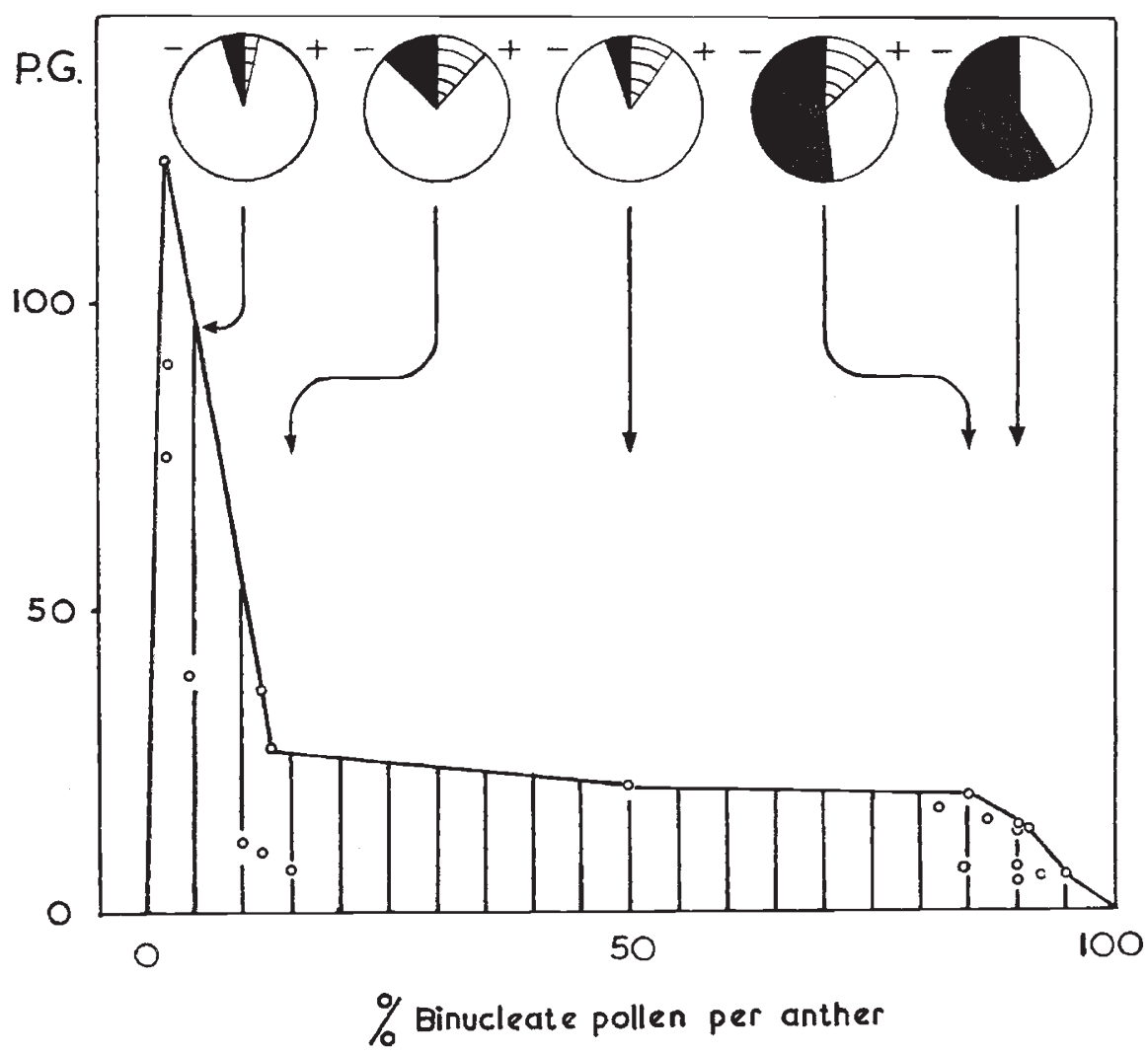

TexT-FIG. 2.-Pollen development assessed by plotting the number of grains observed at metaphase against the proportion of binucleate pollen grains in an anther of Allium paniculatum. The latter indicates the phase of anther development. The top circles in the figure show the proportions of sub-haploid, haploid and hyper-haploid pollen grains as black, white and lined sectors respectively, at different phases of anther development.

(ii) Numerical hybrids. In triploids of A. carinatum and A. rubellum, chromosome numbers in the pollen grains vary around means of I I 7 I and I I.44 respectively and the distribution curves are skewed showing chromosome loss (text-fig. 3). The frequency of pollen with less than twelve chromosomes is higher than that of pollen with more than twelve chromosomes. However, in the pentaploid A. neapolitanum there is no chromosome loss and the distribution curve is very slightly narrowed (text-fig. 4). This is in contrast to $5^{8}$ per cent. chromosome loss in Tulipa clusiana, where the cell size is larger and the chromosomes smaller than Allium and also Tradescantia (Upcott and Philp, 1939).

The present data on Allium (text-fig. 4, table 4) are similar to earlier 
reports on triploids of $A$. carinatum, A. nutans (Levan, I933; 1936), Tulipa lanata (Upcott and Philp, r939) and Hyacinthus orientalis (Darlington and Mather, 1944). In all these cases 5-20 per cent. chromosome loss has been reported, but there is no reference to telocentrics which are very likely to be formed in triploids. In this respect observations on $A$. rubellum (table 4 ) are of interest because 23 per cent. pollen grains have telocentrics.

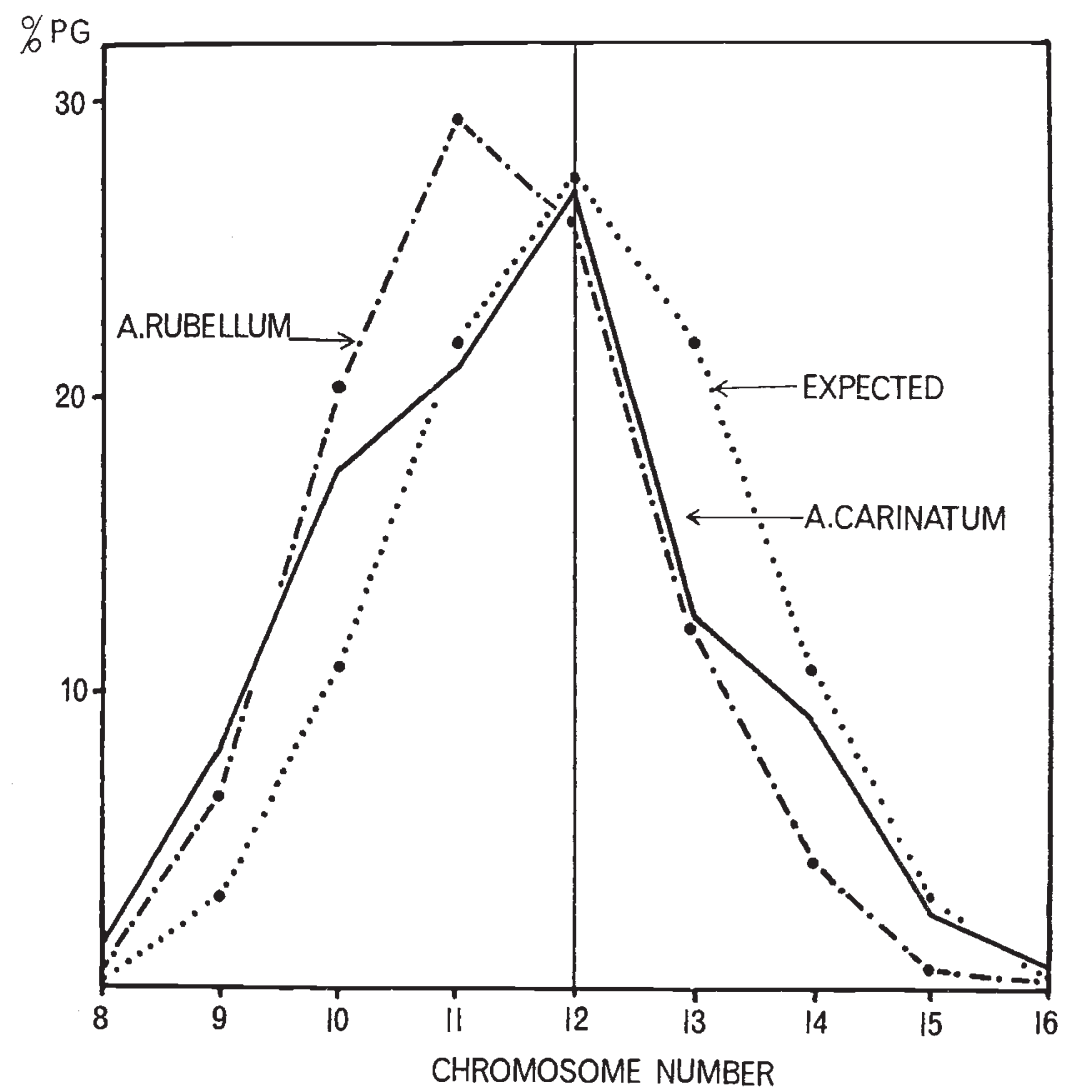

TEXT-FIG. 3.-The distribution of whole chromosomes in the pollen grains of Allium rubellum and Allium carinatum $(3 x=24)$. The latter data based on 278 counts, including 226 from Levan (I 933), from seven different samples with mean chromosome number per grain varying between $I_{I} I$ and II 8 with a spurious loss of $22.5-5^{\circ}$ oo per cent chromosomes.

In Allium rubellum the distribution curve shows 16 per cent. chromosome loss as compared to I $4^{\circ} \mathrm{O}$ per cent. as assessed after including telocentrics ( $c f$. table 4 ).

Earlier reports for A. carinatum (Levan, I933, p. Io9, table I) showed 5-22 per cent. chromosome loss. Levan interpreted this loss as the effect of external factors. In view of the present observations on $A$. paniculatum, chromosome loss which is so variable in different samples of $A$. carinatum seems rather spurious. It is very likely that the heterogeneity amongst different samples is in fact due to the variation in genetic constitution of different pollen grains which enter mitosis at different times or phases of anther development. 


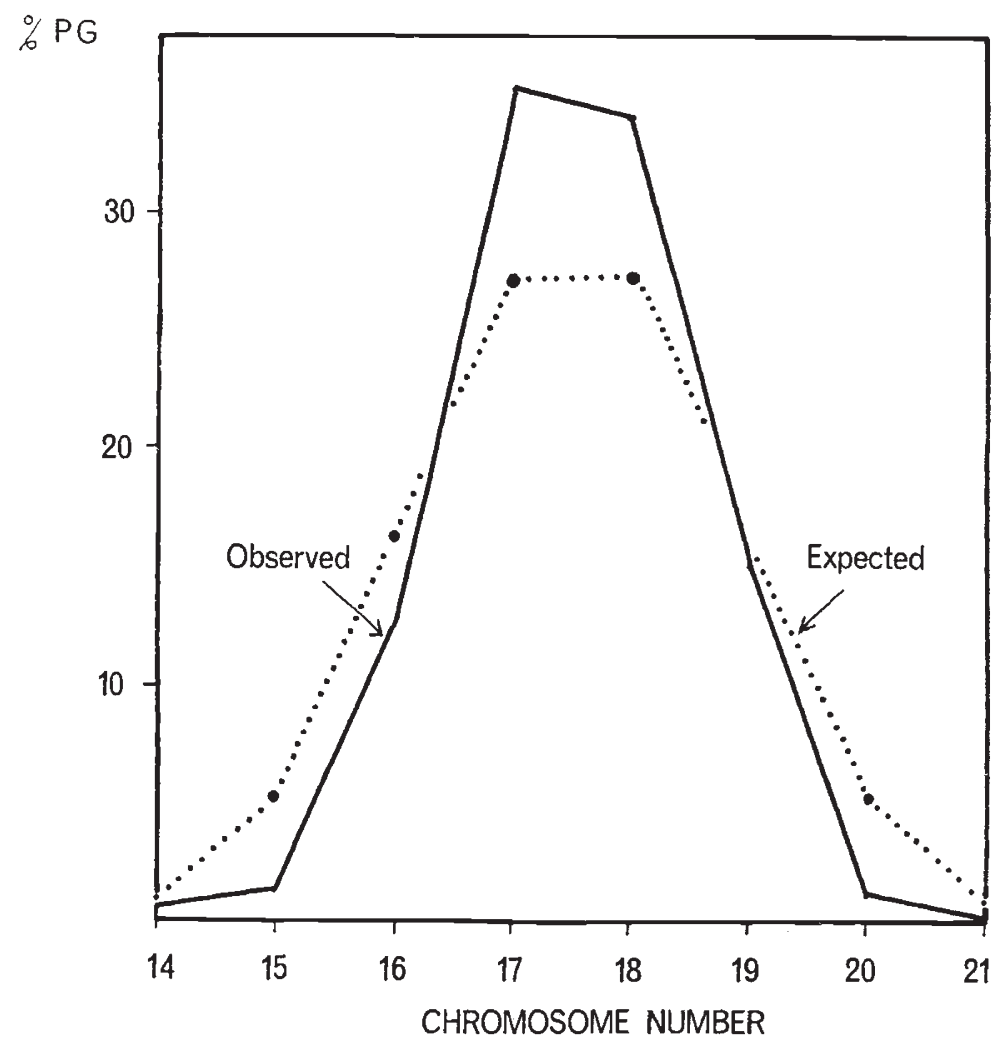

TEXT-FIG. 4.-Chromosome distribution in the pollen grains of Allium neapolitanum $(5 x=35)$. The data are based on 155 counts from ten anthers from five flower buds with phase of development unrecorded.

TABLE 4

Chromosome distribution in the pollen grains of A. rubellum ( $3 \mathrm{x}=24)$ ( 7 anthers, all with 25-37 per cent. binucleate pollen)

\begin{tabular}{|c|c|c|c|c|c|c|c|c|c|}
\hline Telocentrics & & & & & & & & & \\
\hline
\end{tabular}

Mean $=11 \cdot 44 \cdot$ Loss $=14 \cdot 0$ per cent. 
In contrast to Allium, chromosome counts in the pollen grains of triploid Endymion nonscriptus and E. hispanicus show a chromosome gain. Pollen grains with thirteen or more chromosomes have a higher frequency than those with less than twelve chromosomes (Wilson, r959a and $b$ ). In E. hispanicus, an analysis of individual chromosomes shows that about 25 per cent. pollen grains had one or another chromosome represented three times. This leads to an expectation of a corresponding frequency of pollen which would be completely deficient for the same chromosome. Instead only 3 per cent. grains were recorded in the latter category. The timing relationship for the division of the two types of pollen is not evident from the data given. Presumably most of them divide at different times as in $A$. paniculatum, and the skewness of the distribution curve which suggests a chromosome gain is not entirely due to premitotic elimination of the unbalanced grains.

\section{(c) Abnormal mitosis}

In the pollen grains of Allium, as in most of the flowering plants, the spindle is normally formed across the longitudinal axis of the grain resulting in a corresponding polarity of the daughter nuclei. Owing to the genotypic unbalance in some pollen grains of $A$. paniculatum, A. rubellum and $A$. neapolitanum, errors of spindle orientation occur as in Hyacinthus and Tulipa (Upcott, I939). But this can also be due to an environmental effect as in Tradescantia (La Cour, 1949). In $A$. neapolitanum, however, there is a greater diversity of spindle orientation which is accompanied by a dis-harmony in the relationship between chromosome and spindle cycles as in Tulipa (plate II, figs. $c-f$ ) This leads to a lagging of chromosomes and consequently to a delay in the division of their centromeres or to the formation of a micronucleus. Thus the changed polarity of the spindle leads to a failure of normal differentiation between vegetative and generative nucleus, resulting in pollen inviability as in Tradescantia (Sax, 1937).

\section{PHASE AND VIABILITY}

Unlike the Orchidaceae, pollen grain mitoses in Allium are independent of one another. The genotypic constitution of the grains is revealed during division by the form and time of mitosis. In the diploid hybrids, in addition to sub-haploid pollen, some of the haploid grains, which are normal for chromosome number, are genotypically unbalanced also. They reveal their character by the hazy outline of their chromosomes at metaphase or by errors of nuclear differentiation as in A. cernuum (Levan, 1939). They may also do so by the frequency of chromosome breakage as in Tradescantia where these characteristics are genotypic and arise in the hybrids owing to recombination (Giles, I940, I94 I).

In the polyploids, the abnormal mitoses cannot be correlated with particular chromosome numbers, but the principle of the timing of mitosis in relation to the genotypic constitution of the pollen should 


\section{Plate I}

(All figures $\times 135^{0}$ )

Frg. a.-Mitotic complement of Allium paniculatum $(2 x=16)$, showing heterozygosity for centromere position in the pair of nucleolar chromosomes.

Fig. b.-P.m.c. of Allium paniculatum with eight bivalents including two forming proximal chiasmata, presumably owing to hybridity. See also text-fig. I $(a)$.

Fig. c.-First anaphase in p.m.c. of Allium paniculatum showing the division of a univalent along the centromere and a bridge-fragment.

Frg. d.-Misdivision of a chromosome at second anaphase in Allium paniculatum.

Fig. e.-First anaphase in Allium rubellum $(3 x=24)$ showing a bridge, a bridge-fragment and division of two univalents along the centromere.

Fig. f.-Second anaphase in Allium rubellum showing two sister diads of a p.m.c. with telocentrics having arisen from the division of chromatids across the centromere and also a bridge formed by the terminal union of sister chromatids.

FIG. $g$, h.-Sub-haploid pollen grains of $A$. paniculatum. The chromosomes have a rather hazy outline. 


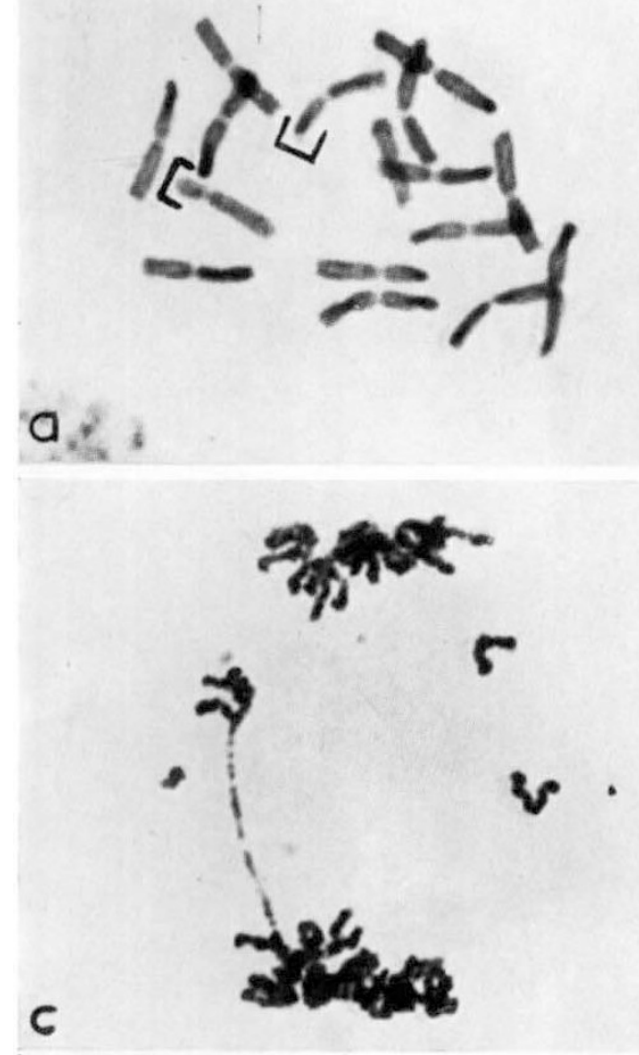

b

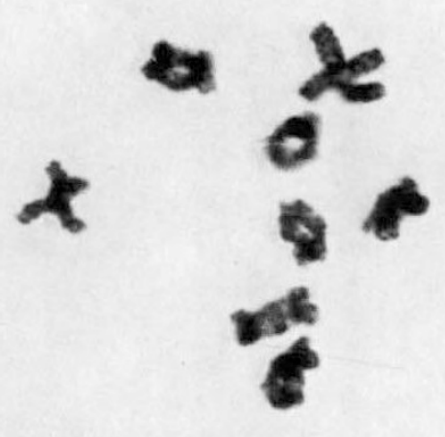

antor
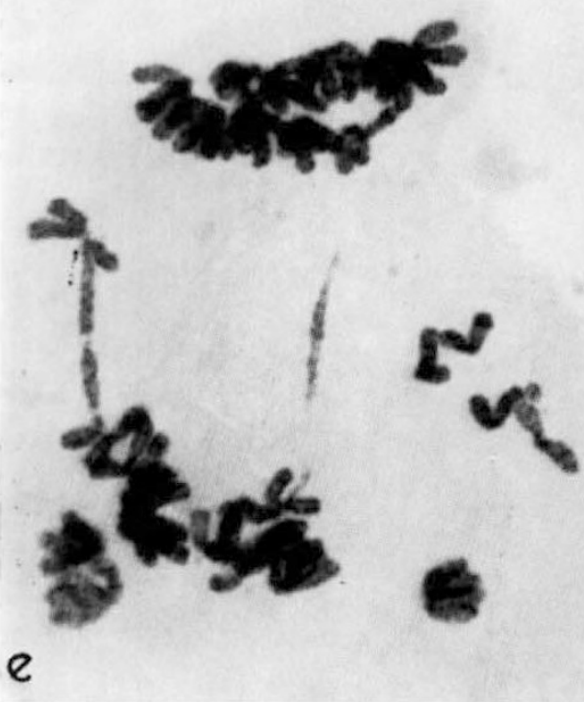

9

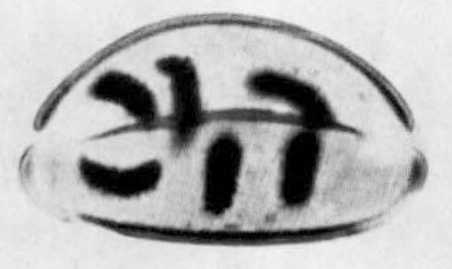

he -

f

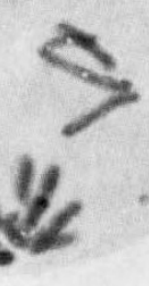

$d$

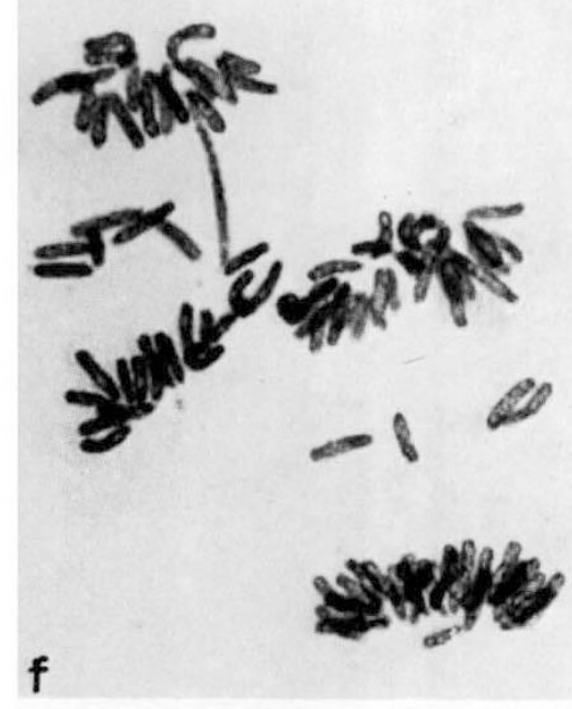

h 
Plate 11

(All figures $\times 1350$ )

Pollen grain mitosis in Allium neapolitanum $(5 x=35)$

Fig. a.-Metaphase with eighteen chromosomes.

Fig. b. - Metaphase with $n=17$.

Fig. c.-Abnormal mitosis showing lagging of a chromosome.

Fig. d.-Distorted nuclear polarity arising from anamolous spindle orientation. Micronucleus derived from lagging chromosomes.

Fig. e.-Distorted nuclear polarity and lagging of chromatids.

Fig. $f$.-As above but the lagging chromatids form bridges. 

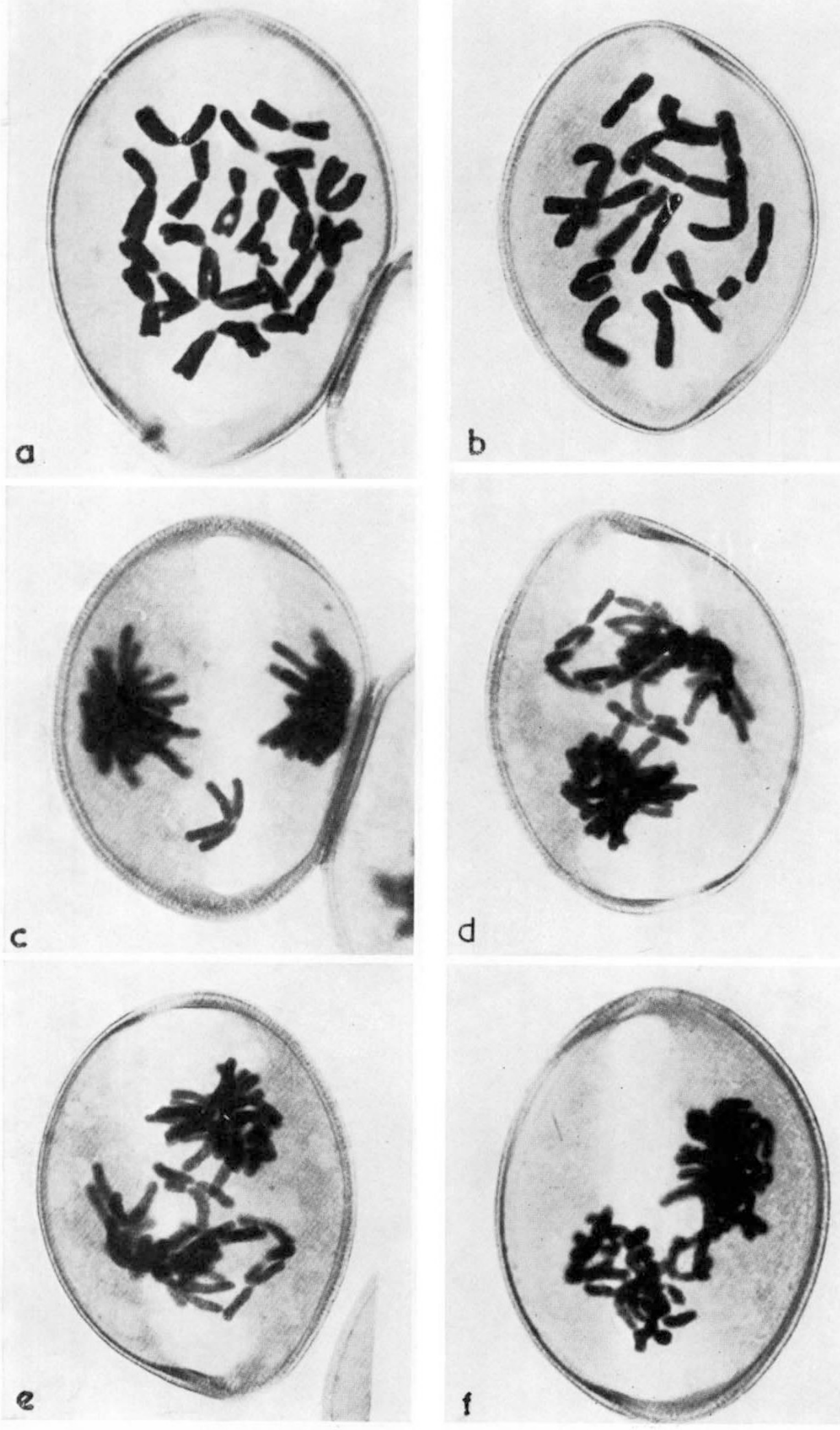
be equally relevant. It could also partly explain the chromosome loss in triploids as inferred by earlier workers. In plants like triploid bluebells, where individual chromosomes can be identified, re-examination of pollen grain mitosis is desirable. Very likely it would reveal that the previously reported nullisomic pollen grains have different times of mitoses from those with the corresponding extra chromosomes. The fact that only some of the chromosome types are observed dividing, although in a very low frequency, suggests that the others also are not entirely eliminated during premeiotic development.

\section{SUMMARY}

I. In structural and numerical hybrids of Altium, pollen grains vary in the time and form of their mitoses.

2. Allium paniculatum $(2 n=2 x=16)$, with failure of pairing, shows misdivision of univalents, and bridges with and without fragments during meiosis. It produces pollen grains with six to ten chromosomes including telocentrics. The unbalanced pollen grains with haploid and sub-haploid chromosome numbers reach mitosis usually later than the balanced ones.

3. Allium carinatum and A. rubellum $\left(2 n=3^{x}=24\right)$ produce pollen grains with chromosome numbers conforming to binomial distribution but showing loss. In the latter, however, telocentrics arise from misdivisions at meiosis and are found at very high frequency in the pollen grains.

4. There is no chromosome loss in Altium neapolitanum $\left(2 n=5^{x}=35\right)$. The distribution curve is narrowed perhaps due to limiting cell size favouring $17: 18$ distribution.

5. Abnormal mitoses resulting in a failure of proper nuclear polarity occur in some pollen grains of $A$. paniculatum, A. rubellum and A. neapolitanum. This evidently results in pollen inviability.

6. Failure of synchronisation in the spindle and nuclear cycles causes lagging of chromosomes which fail to divide forming micronuclei in the pollen grains of $A$. neapolitanum.

Acknowledgments.-I am very pleased to express my gratitude to Professor C. D. Darlington, F.R.S., for his helpful advice during the course of this work.

\section{REFERENCES}

BeLling, J. 1925. The origin of chromosomal mutation in Uvularia. F. Genet., 15, 245-266.

BROCK, R. D. 1955. Chromosome balance and endosperm failure in hyacinth. Heredity, 9, 199-222.

Celarier, R. P. 1955. Desynapsis in Tradescantia. Cytologia, 20, 69-83.

CONGER, A. D. 1940. Chromosome deficiencies in microspores of Tradescantia. 7. Hered., 3I, 338-341.

Darlington, C. D. 1936 . The external mechanics of chromosomes. Proc. R. Soc. B. I2I, 264-3r 9 .

DARLINGTon, c. D. 1936. Evolution of Genetic Systems. Oliver \& Boyd, Edinburgh and London. 
Darlington, c. D. 1960. Review on, Blakeslee: The genus Datura. By A. G. Avery, S. Satina and J. Rietsema. Ronald Press, New York. Heredity, I4, 45I-452.

DARLiNGTON, C. D., AND KEFALLINOU, M. 1957. Correlated chromosome aberrations at meiosis in Gasteria. Chromosoma (Berl.), 8, 364-37o.

DARLington, C. D., AND LA COUR, L. F. 1945. Chromosome breakage and nucleic acid cycle. F. Genet., 46 , $180-267$.

DARLINGTON, C. D., AND MATHER, K. 1944. Chromosome balance and interaction in Hyacinthus. 7. Genet., 46, 52-61.

GILES, N. H. 1940. Spontaneous chromosome aberrations in Tradescantia. Genetics, $25,69-87$.

GILES, N. H. 194I. Spontaneous chromosome aberrations in triploid Tradescantia hybrids. Genetics, 26, 632-649.

Khoshoo, T. N., AND Sharma, v. B. 1959a. Cytology of the pentaploid Allium neapolitanum. Cytologia, 24, 304-314.

kHoshoo, T. N., AND sharma, v. B. I959b. Cytology of the autotriploid Allium rubellum. Chromosoma (Berl.), Io, 136-143.

LA COUR, L. F. 1949. Nuclear differentiation in the pollen grain. Heredity, 3, 319-337.

LANE, G. R., AND EVANS, E. P. Ig66. X-ray induction of chromosome aberrations in relation to nuclear volume in Tradescantia bracteata. Heredity, 19 (suppl.), 13 I-I 40.

LeVan, A. 1933. Cytological studies in Allium. III. Allium carinatum and Allium oleraceum. Hereditas (Lond), I8, Iо I-I I 4 .

LEVAN, A. 1936. Studien an Allium schoenoprasum. Hereditas (Lund), 22, I-I 28.

LEVAN, A. 1939. Amphibivalent formation in Allium cernuum. and its consequence in the pollen. Bot. Not., 1939, 256-26o.

LEWIS, K. R., AND JOHN, B. 1964. The matter of Mendelian Heredity. Churchill, London.

MORRISON, J. w. 1953. Chromosome behaviour in wheat monosomics. Heredity, 7, 203-217.

SAX, K. 1937. The effect of variation in temperature on nuclear and cell division in Tradescantia. Am. 7. Bot., 24, $218-225$.

UPCOTT, м. 1939. External mechanics of chromosomes. VII. Abnormal mitosis in pollen grains. Chromosoma (Berl.), I, I 78-19o.

UPCOTT, M., AND PHILIP, J. 1939. The genetic structure of Tulipa. IV. Balance, Selection and Fertility. 7. Genet., $3^{8}, 9^{1-123 .}$

VED BRAT, S. 1965. Genetic systems in Allium. I. Chromosome variation. Chromosoma (Berl.), I6, 486-499.

wILson, J. Y. 1959a. Cytogenetics of triploid bluebells. Endymion nonscriptus (L) and E. hispanicus (Mill.) Chouard. Cytologia, 23, 435-446.

wiLson, J. Y. 1959b. A study of individual chromosome composition of the various chromosome number classes at pollen mistosis. I. In a triploid plant. Cytologia, $24,466-477$. 